\title{
Das pequenas produções à agroindústria: suinocultura e transformações na paisagem rural em Chapecó, SC
}

\begin{abstract}
Resumo
O município de Chapecó, localizado no oeste do estado de Santa Catarina, passou por diversos momentos de transformações ambientais desde a sua criação, em 1917. Mesmo antes desse período, já havia grupos humanos habitando o local e interagindo com o mundo natural. No entanto, partir do século $X X$, a região Oeste de Santa Catarina passou a receber migrantes de descendência europeia oriundos de outras colônias, principalmente, do Rio Grande do Sul, em busca de terras para lavoura. O governo do Estado concedeu terras devolutas a algumas companhias colonizadoras, as quais ficaram encarregadas por dividir essas terras em lotes que seriam vendidos aos colonos. Este estudo visa analisar os desdobramentos em torno da criação dos suínos, a partir da segunda metade do século $X X$, ligada à expansão da agroindústria e às transformações ambientais na região Oeste de Santa Catarina. Mesmo com a longa datação de ação antrópica na região, é inegável que nos últimos cinquenta anos do século $\mathrm{XX}$, as transformações ambientais tornaram-se mais intensas.
\end{abstract}

Palavras-chave: Suinocultura. Chapecó. História Ambiental.

\section{Samira Peruchi Moretto}

Doutora em História pela Universidade Federal de Santa Catarina (UFSC). Professora da Universidade Federal da Fronteira Sul (UFFS). Chapecó - SC - BRASIL samiraperuchimoretto@yahoo.com.br orcid.org/0000-0002-5276-2512

\section{Marlon Brandt}

Doutor em História pela Universidade Federal de Santa Catarina (UFSC). Professora da Universidade Federal da Fronteira Sul (UFFS). Chapecó - SC - BRASIL marlonbrandt@yahoo.com.br orcid.org/0000-0002-0392-4167

\section{Para citar este artigo:}

MORETTO, Samira Peruchi; BRANDT, Marlon. Das pequenas produções à agroindústria: suinocultura e transformações na paisagem rural em Chapecó, SC. Tempo e Argumento, Florianópolis, v. 11, n. 26, p. 229 - 254, jan./abr. 2019.

DOI: $10.5965 / 2175180311262019229$

http://dx.doi.org/10.5965/2175180311262019229 


\title{
From small production to agribusiness: swine farming and transformations in the rural landscape in Chapecó, SC
}

\begin{abstract}
The municipality of Chapecó, located in the west of the state of Santa Catarina, underwent several moments of environmental transformation since its creation in 1917. Even before this period, there were human groups inhabiting the area and interacting with the natural world. However, from the twentieth century, the western region of Santa Catarina began to receive migrants of European descent from other colonies, mainly from Rio Grande do Sul, in search of land for farming. The government of the state granted vacant lands to some colonizing companies, which were in charge of dividing these lands in lots that would be sold to the settlers. This study aims to analyze the developments around the pig farms, from the second half of the twentieth century, related to the expansion of agroindustry and environmental transformations in the western region of Santa Catarina. Even with the long-standing record of anthropogenic action in the region, it is undeniable that in the last fifty years of the twentieth century, environmental transformations have become more intense.
\end{abstract}

Keywords: Swine. Chapecó. Environmental History.

\section{A criação dos suínos: o surgimento da agroindústria}

No oeste de Santa Catarina, a indústria agropecuária emergiu a partir da década de 1940. Era prática comum comercializar o excedente da produção agropecuária, que era muito diversificada. A comercialização da produção foi facilitada com a abertura e instalação de vias de rodagem e das ferrovias próximas à região. As cobranças pela melhoria das vias de rodagem eram frequentes nos jornais locais. Em 30 de julho de 1939, o jornal A voz de Chapecó publicou um artigo intitulado "Estradas péssimas", no qual eram nomeados os responsáveis pelas melhorias: 
Pessoas que viajaram para os distritos de Itapiranga, Mondai, Passarinhos e S. Carlos, informam-nos que a estrada estadoal, de ligação dos ditos distritos a esta cidade, está em péssimas condições. Sabemos que o sr. Fiscal Eleutério Lemes não tem responsabilidade pelo descaso a que está votada esse importante via de comunicação. (A VOZ DE CHAPECÓ, 30/07/1939)

As condições dessas estradas eram também um dos principais obstáculos para a colonização, que poucos anos depois continuava, como afirmou Léo Waibel, em seu estudo sobre a colonização do Sul do Brasil, "semeando povoados ao longo das estradas e rios, na direção norte, onde está o sertão desabitado" (WAIBEL, 1949, p. 233).

A colonização trouxe um conjunto de novos usos do espaço e técnicas, formadas, nas palavras de Milton Santos (2006, p. 29), por "um conjunto de meios instrumentais e sociais, com os quais o homem realiza sua vida, produz e, ao mesmo tempo, cria o espaço". A partir de então passa a ocorrer no Oeste uma reestruturação das relações ecológicas e sociais para a produção de recursos, construindo e (re)produzindo paisagens nas novas terras a partir de suas práticas socioculturais e de uso do espaço.

A paisagem, vista sob o viés da Geografia, é a expressão materializada do espaço geográfico, sendo "o conjunto das formas que, num dado momento, exprimem as heranças que representam as sucessivas relações entre o homem e a natureza" (SANTOS, 2006, p. 103-104). Porém, esta não detém somente uma dimensão espacial, mas também histórica. A paisagem seria, dessa maneira, o resultado da acumulação de atividades que expressam uma imbricada relação envolvedora de diferentes objetos e ações em variadas escalas temporais. É o que se pode perceber, por exemplo, na trajetória da criação de porcos no Oeste de Santa Catarina, analisando, nesse caso, a suinocultura e a sua presença na paisagem rural de Chapecó, Santa Catarina.

A criação de suínos, embora comumente associada à colonização e à figura do colono de origem italiana ou alemã que migrou para o Oeste catarinense a partir da década de 1920, remete pelo menos ao século XIX, sendo um elemento comum na paisagem das florestas. A presença desses animais e a importância para o consumo humano pode ser constatada no Sul do Brasil, inicialmente na região litorânea e posteriormente no planalto, acompanhando a formação das primeiras fazendas de 
criação de gado nos campos, a partir do século XVIII. Porcos que acompanharam o povoamento das áreas de florestas nos interstícios das grandes fazendas das áreas de campo, deslocando-se a partir delas para o Oeste catarinense e Sudoeste paranaense a partir do século XIX (BRANDT, 2012).

Essa presença está ligada ao fato de, por ser um animal onívoro, alimentar-se de frutos caídos, sementes, raízes, relva e de qualquer animal pequeno, encontrado, por exemplo, nas florestas, despendendo menor necessidade de manejo que os herbívoros bois, cavalos e mulas (CROSBY, 1993). Outro fator importante para a adoção da criação do animal é sua capacidade de conversão de alimento em carne e banha em comparação a outros animais, como os bovinos. Os porcos convertem cerca de um quinto do que comem em alimento para consumo humano, contra aproximadamente um vigésimo dos bovinos, além do menor trabalho e tempo necessário para o abate ou comercialização (LAGO, 1988). Esse conjunto de elementos foi um dos responsáveis pela sua dispersão, acompanhando de forma conjunta a ocupação europeia do território. O porco foi e ainda é, como aponta Warren Dean (2004, p. 91), responsável por diversas situações de conservação e/ou disseminação da vegetação florestal, embora pudesse promover impactos na fauna local, ao competir com espécies nativas por alimento e espaço.

Nesse contexto de ocupação, campos e florestas representavam não apenas paisagens distintas, mas também diferentes modos de vida e possibilidades de independência dos laços até então costurados com as fazendas pastoris. Essa população poderia viver da criação de animais, extrativismo da erva-mate, caça, pesca e agricultura de subsistência. Formavam o que Maurício Vinhas de Queiroz (1981) denominou como “roça cabocla”, caracterizada, conforme Arlene Renk (2006, p. 107) por "uma prática costumeira de dividir as terras em terras de plantar e terras de criar".

Nas áreas destinadas às "terras de plantar”, ocorria uma policultura com rotação de terras, sob o regime da queimada de pequenas áreas em meio à floresta. Ocupavam áreas pequenas, pois o cultivo era destinado à subsistência e como complemento à alimentação animal. Geralmente fechada, por encerras, valetas ou troncos de árvores, concentravam, conforme Maurício Vinhas de Queiroz (1981, p. 36), no milho “o centro da lavoura, consorciado ao feijão e por vezes à abóbora e à melancia". 
As “terras de criar”, eram mais extensas se comparadas às áreas para a plantação. Abrangiam tanto a floresta quanto pequenas áreas de campo, abertas naturalmente ou não, utilizadas para a criação de bois e cavalos, enquanto a floresta era utilizada na criação de porcos. Criados soltos, os animais compartilhavam os mesmos espaços com criadores vizinhos em uma forma de suinocultura extensiva. Por necessitarem de pouco manejo, bastava soltá-los na floresta onde engordavam se alimentando de frutas, pequenos animais e principalmente do pinhão. Esses animais eram destinados tanto à subsistência das famílias quanto à comercialização local em cidades próximas. Caso fossem comercializados, os animais, depois de arrebanhados, eram confinados em uma encerra de milharal aberta em meio à floresta ou em um mangueirão para continuar a engorda e, de lá, seguiam para alguma vila ou matadouro próximo para produção principalmente de banha (BRANDT; NODARI, 2011).

Essa forma de criação dos animais à solta requeria amplas áreas, sendo que cada animal necessitava, como aponta Roberto Lobato Corrêa (1970, p. 93), de cerca de cinco hectares de floresta, ou seja, não pode coexistir com uma ocupação mais densa. "Ela é, pois, uma atividade de áreas de muito baixa densidade demográfica, e à medida que o povoamento de colonos progredia, essa atividade afastava-se para áreas mais remotas". Assim, essa forma de criação passou a desaparecer à medida que a colonização no Oeste catarinense avançava.

Eunice Nodari (2009, p. 57) afirma que com a colonização da região, "a utilização do espaço até então habitado, principalmente, por caboclos sofreria modificações e remodelações com a chegada desses novos moradores, no decorrer dos anos". Ao se instalarem nas terras, os colonos passaram a derrubar a floresta para a formação de lavouras cuja produção era voltada à comercialização de seus produtos, principalmente o trigo e o milho, diferente das pequenas roças formadas nas "terras de plantar" (BRANDT; NODARI, 2011). Com o adensamento demográfico promovido pela colonização, passaram a ocorrer, além da expropriação da população posseira que antecedia a colonização, diversas situações de tensão, causadas pela incompatibilidade entre as formas de uso e acesso à terra. Muitas delas estão relacionadas à questão da invasão dos animais criados à solta nas roças dos colonos. Paulatinamente, os criadores que não perderam suas terras 
ao longo da colonização sentiam a redução cada vez maior dos espaços de uso em comum, o que impedia o livre trânsito dos seus animais, sobretudo os porcos, agora confinados em mangueiras e chiqueiros, à maneira dos colonos (BRANDT, 2015).

Paulo Fernando Lago (1988, p. 289) pondera que o relevo das regiões colonizadas, em vales de encostas íngremes, onde o terreno possuía, em muitos casos, uma declividade acentuada, apresentava restrições à criação do gado bovino que era empregado, sobretudo, para o consumo familiar de leite e derivados e como animal de tração. Dessa maneira, a criação de suínos no Oeste, surgia como uma alternativa, principalmente se criados de forma confinada, como eram criados os porcos pelos colonos, passando a desempenhar um importante papel na economia dessas famílias. Essa forma de criação era compatível com a dimensão média das propriedades dos colonos, que possuíam cerca de 10 alqueires ou 24,2 hectares, desde que adotassem o que ele denominou como "binômio milho/porco". Esse binômio, no entanto, não foi invenção dos colonos que se estabeleciam no Oeste. Ele já era observado em outras áreas de colonização, como na região de Urussanga e Vale do Itajaí, da mesma forma que era também observado no Meio-Oeste norte-americano e na porção norte dos pampas argentinos, onde já se constatava "a eficácia do enlace entre o mais notável cereal do Novo Mundo e a espécie porcina" (LAGO, 1988, p. 289).

Por esse fato, era comum encontrar produção de milho nas regiões criadoras de suínos. Além do consumo, a plantação de milho servia para engordar os suínos, uma vez que a banha era o principal produto de interesse na criação desses animais, sua engorda era importante. Costumava-se cercar a plantação de milho e, em sua safra, soltar os suínos dentro dessa área. Essa forma de criação em encerras pode ser visualizada na figura 01. Na imagem, aparecem os porcos confinados para a engorda. 
Figura 01: Suínos criados no cercado de madeira em Pinhalzinho, SC, na década de 1950.

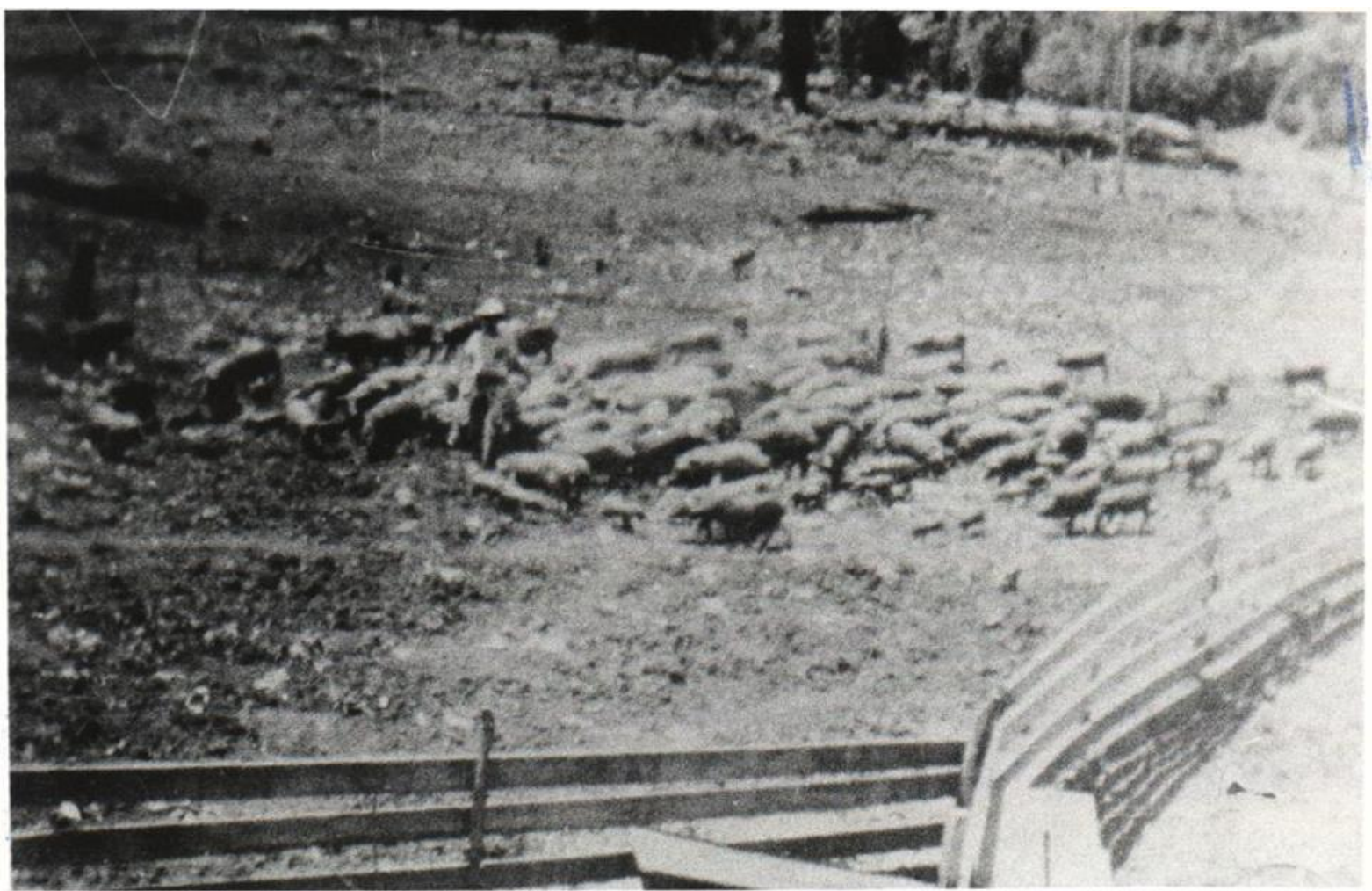

Fonte: Acervo Fotográfico do Museu Histórico de Pinhalzinho.

O agricultor Bruno Zimmermann relata, ao ser entrevistado, o processo de engorda dos porcos através das plantações de milho:

[...] e daí eles plantavam o milho e quando o milho chegava a lourar, daí eles, é... eles largavam os suínos. [...] então eles deixavam o porco inté terminar aquela dita lavoura de milho, inté que ele consumia aquilo e daí levavam no comércio. Daí eles tocavam ele fora, às vez quilômetros e noites e noites que eles tocavam pra lá e pra cá inté que eles chegavam numa estrada, às vez inté perto o comércio tocava. E daí esse tal do porco ia pro frigorífico. De lá pra frente daí é com caminhão, com outros meios de transporte. (ZIMMERMANN, 2017, p. 2)

A criação de suínos e a produção do milho foram responsáveis pelo crescimento econômico na região. Além das famílias que migraram para trabalharem como agricultoras, passaram a se instalar diversos comerciantes, que atuavam na compra de produtos agrícolas e animais, sobretudo porcos, e pequenos artesãos e produtores de banha e derivados de carne suína. Sua produção era destinada não só ao comércio local, mas também à venda para outras regiões, cujo transporte era feito pela Estrada de Ferro 
São Paulo - Rio Grande, que interligava a região com o Sul e o Sudeste do país. Próximos às estações, encontravam-se também comerciantes que despachavam, via-férrea, alfafa e suínos para o Paraná, São Paulo, Rio Grande do Sul e para frigoríficos e pequenos produtores de banha e derivados de carne suína do Rio Grande do Sul e Paraná, ao que se juntariam, pouco tempo depois, os formados no Oeste e Vale do Rio do Peixe de Santa Catarina (CORRÊA, 1970; ESPÍNDOLA, 1999; FERRARI, 2003), promovendo um aumento na demanda por porcos na região.

O aumento na demanda pela banha relacionava-se, segundo Corrêa (1970, p. 89), à expansão do mercado consumidor, "que o comércio importador não poderia suprir em função dos preços elevados dos artigos importados, possibilitando o aparecimento de unidades fabris produtoras". Com o surgimento dos primeiros frigoríficos na segunda década do século XX, a criação de animais passou a visar também o mercado nacional, principalmente São Paulo e Rio de Janeiro, que passavam por um processo intenso de urbanização, provocando um aumento no consumo de derivados de carne e banha. Em Santa Catarina, a banha desempenhou um importante papel na pauta geral das exportações ao longo da primeira metade do século $X X$, tendo como destino principal a região Sudeste (BOSSLE, 1988; IBGE, 1986). A banha era um produto valorizado, empregado tanto no cozimento quanto na conservação de alimentos (LAGO, 1988; VALENTINI, 2006), principalmente em uma época em que os óleos vegetais tinham pouca inserção no mercado ou eram produtos regionais, como o azeite de dendê. As principais raças de porcos criados na época, como Macau, Caruncho, Tatu, Piau, Canastra e Canastrão, variedades rústicas de origem ibérica e asiática, eram adaptados às condições locais, apresentando resistência a doenças e facilidade de reprodução, sendo próprias para a produção de banha (OLINGER, 1969).

Conforme Pertile (2008, p. 92), a inserção do estado de Santa Catarina no mercado brasileiro, com a produção de banha, culminou na expansão dos frigoríficos na região oeste. Os comerciantes, através do comércio de excedentes dos produtores rurais, conseguiram obter lucro para investir em frigoríficos quando, a partir da década de 1940, passou a ser mais lucrativo realizar o abate de animais e a venda da banha e da carne suína, do que o comércio de suínos vivos para São Paulo. 
Com o passar das décadas e o aumento do consumo da carne de suínos, houve a necessidade de alterar o produto obtido através da criação; o foco não era mais a banha, com potencial de conservação de alimentos, mas sim a carne. Dessa maneira, tornou-se fundamental a existência de um frigorífico localizado mais próximo do produtor do que as indústrias para onde eram vendidos anteriormente, para que fossem processados muitas vezes fora do estado. A especulação sobre a criação do primeiro frigorífico em Chapecó foi recebida com grande entusiasmo, como pode ser percebido através da notícia abaixo:

Parece incrível, mas se for mesmo fundado um frigorifico em Chapecó, ele trará calor, porém, calor para a nossa vida econômica, calor para o movimento comercial da cidade, esquentando e contribuindo para o bem-estar geral da coletividade. Representaria o frigorifico uma força importante, imponente, e respeitável não só em Chapecó, mas no oeste catarinense todo, que iria beneficiar-se com tão vital indústria. [...] Uma coisa, porém, é certa: o povo de Chapecó será prejudicado, caso não seja criado o frigorifico nesta cidade [...] (MACHADO, 1952, p. 1)

O crescimento industrial de Chapecó está inserido em um contexto nacional de expansão do setor, que ocorreu a partir de 1950 e 1960 (BAVARESCO, 2017). Esse processo de industrialização foi intensificado através da instalação de novos frigoríficos, que industrializavam aves e suínos, em uma onda desenvolvimentista. Os governos estaduais e municipais passaram a incentivar a instalação de indústrias, como é possível observar na Lei municipal $n^{\circ}$ 12, de 24 de março de 1970, que visava conceder benefícios a indústrias para que se estabelecessem em Chapecó. A lei previa a doação por parte da prefeitura de Chapecó sob o montante do capital investido em novas indústrias “a) Até $5 \%$ para aquisição do terreno necessário; b) até 3\% para as obras de terraplanagem, vias de acessos e serviços similares; c) até $2 \%$ para a construção da rede de energia elétrica até o local, inclusive no fornecimento do equipamento necessário" (CHAPECÓ, 1970).

No entanto, não foi apenas Chapecó que abrigou as agroindústrias. Várias empresas se instalaram no Vale do Rio do Peixe na década de 1940, como a Sadia Avícola S.A., no município de Concórdia, ocasionando o transporte de suínos criados em Chapecó para o Vale do Rio do Peixe. Em Chapecó, na década de 1950, duas agroindústrias iniciaram suas atividades, a primeira em 1952, denominada S. A. Indústria e Comércio Chapecó (SAIC) e a outra em 1956, a Indústria e Comércio Marafon LTDA. (PERTILE, 2008, p. 91). 
Além do setor privado, as cooperativas que atuavam no ramo agropecuário também vivenciaram uma ampliação. O incentivo ao cooperativismo ocorreu não só devido à pequena produção gerada pelas pequenas propriedades, mas também como forma de atender aos objetivos do governo de alcançar uma produção maior e melhorada, que fosse compatível com o novo modelo econômico (FORNECK; LUBENOW, 2017). Ocorria, dessa forma, a modernização do campo e a implantação de novos sistemas de produção para criação de animais.

No cenário atual, Chapecó se destaca em nível nacional por sua produção agroindustrial ligada, principalmente, à suinocultura e à avicultura. Porém, as primeiras empresas instaladas na década de 1950 tinham estruturas físicas muito mais simples do que o formato pelo qual as conhecemos atualmente. As figuras 02 e 03 correspondem à fase inicial da instalação de frigoríficos em Chapecó.

Figura 02: Porcos no frigorífico SAIC, em 1957.

Figura 03: Frigorífico de suínos em Chapecó, 1957.

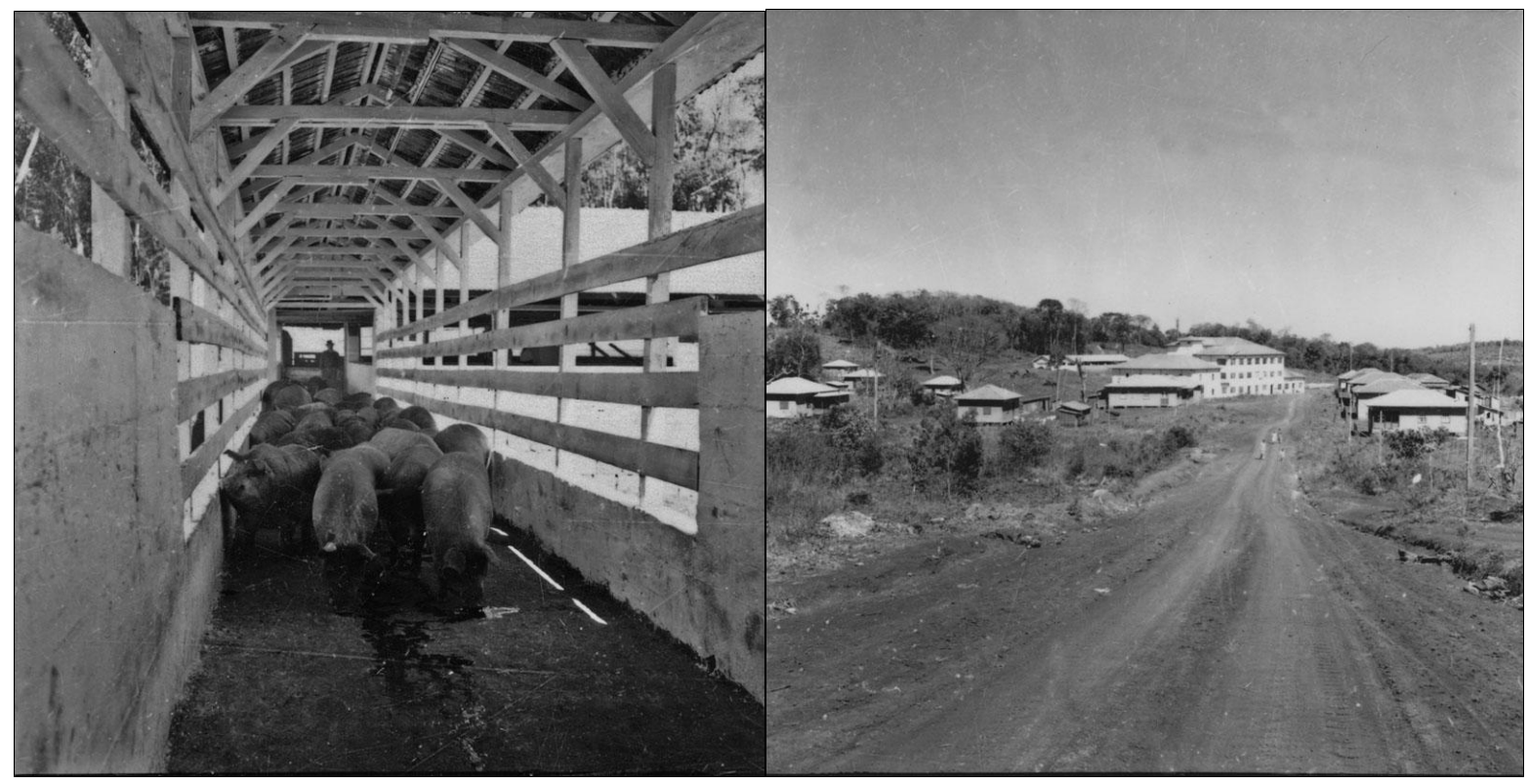

Fonte: IBGE (1957). Acervo dos trabalhos geográficos de campo.

Para chegar ao patamar de produção atual, foram empregados mecanismos que possibilitaram obter uma criação de animais mais eficiente. Nesse aspecto, podemos relacionar o auxílio técnico oferecido aos produtores, que repassavam as técnicas que seriam mais adequadas para atingir o resultado desejado, desde instruções sobre o local de criação dos animais até sobre a alimentação que deveria ser fornecida a eles. 
Todavia, a ampliação das indústrias do setor de alimentos em Chapecó acarretou em mudanças para os produtores quanto à criação de animais. O processo de colonização de Chapecó propiciou as características dos imóveis rurais baseadas na predominância da pequena propriedade, da agricultura familiar e na diversidade de cultivos. Conforme o relatório da Empresa Catarinense de Pesquisa Agropecuária (EMPASC, 1993) de 1976, em Santa Catarina, 83,34\% dos imóveis rurais eram minifúndios. O grande percentual de imóveis rurais seguindo o modelo de agricultura familiar, aliado à instalação e desenvolvimento da agroindústria na região deveu-se ao sistema de produção integrada, adotado para a criação de aves e suínos, em que há uma relação entre produtores e indústrias.

No sistema integrado de produção, a agroindústria fica incumbida de fornecer aos produtores, inovações relacionadas ao beneficiamento da produção, como rações, medicamentos, genética, assistência técnica, cabendo aos agricultores as instalações, a mão de obra, o manejo dos dejetos, despesas com água e energia (MIELE; WAQUIL, 2007, p. 80). Na figura 04, podemos observar um criadouro de suíno moderno, onde as instalações zelam pela maior eficiência na produção. A higiene e as condições animais são inspecionadas pelas empresas, visando melhor qualidade do produto final.

Figura 04: Baias para criação de suínos, 2013.

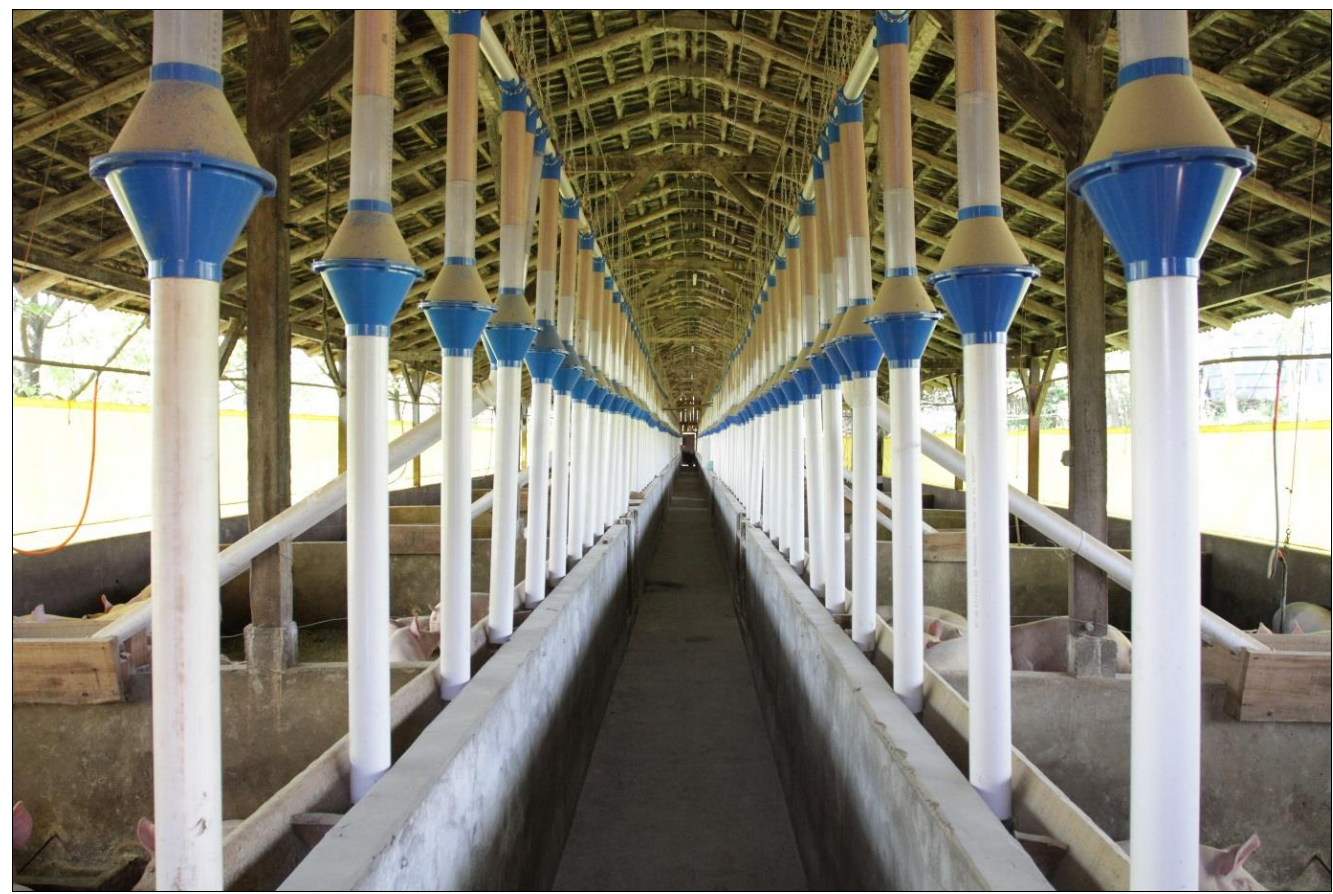

Fonte: MACHADO; MARANGONI; HEFFEL, 2013. Acervo: Aurora Alimentos. 
No sistema integrado, a agroindústria controla a produção, determinando inclusive o momento do abate. O produtor comercializa apenas com aquela empresa, que determina tudo o que é relativo à criação dos animais, como por exemplo, a introdução de novas raças de suínos, que produziam mais carne do que banha. Conforme Paim (2006, p. 11), o grupo Sadia trouxe reprodutores e matrizes da raça Duroc Jersey, importados dos EUA e as raças europeias denominadas Large White e Landrace. As características que permitiam identificar o porco tipo carne eram:

1) crescimento rápido, para alcançar o mercado de 90 a 105 quilos, em seis meses ou menos, nas condições da fazenda onde é produzido; 2) comprimento da carcaça de 75 a $80 \mathrm{~cm}$; 3) espessura média do toucinho de 3 a $4 \mathrm{~cm}$; 4) área da seção transversal do lombo de, no mínimo, $24 \mathrm{~cm}$; e 5) rendimento da carcaça resfriada de 50 ou mais por cento nos cortes indicadores de carne (pernil), lombo, copa e paleta. (FOLHA D'OESTE, 1970, p. 6)

Ao mesmo tempo em que há um aumento no abate de suínos em Santa Catarina passa de 617 mil cabeças, em 1960, para 1,261 mi, em 1970, e 3,882 mi cabeças em 1980, “inicia-se um forte processo de centralização em favor das cinco maiores marcas. Em 1968, os quatro maiores frigoríficos eram responsáveis por $66,6 \%$ do abate total de suínos no Estado, percentual que em 1978 aumentou para 70,5\%; e em 1984 para 90,8\%" (GOULARTI Filho, 2002, p. 310, apud MIRANDA; MIELE, 2009). Houve uma redução substancial nos abates em menores frigoríferos e na produção de banha.

A Empresa Brasileira de Pesquisa Agropecuária (EMBRAPA) investiu em pesquisas de melhoramento genético de suínos, visando mais produção de carne por quilo de animal e redução da produção de banha. Um exemplo desse incentivo é o lançamento do chamado porco light, o porco Embrapa MS5, resultado do cruzamento de três raças, na feira Expointer de 1996. A partir de novos estudos, foi lançada a versão melhorada, o MS115 - chamado a nova geração light, em 2008, figura 05. Segundo a EMBRAPA, os porcos da nova geração light são "animais pesados, mas com carne magra e baixa espessura de toucinho. Pode ser abatido com $115 \mathrm{Kg}$, mantendo a conversão alimentar da versão de 90 Kg" (FOLDER, 2008). 
Figura 05: Folder Embrapa MS115.

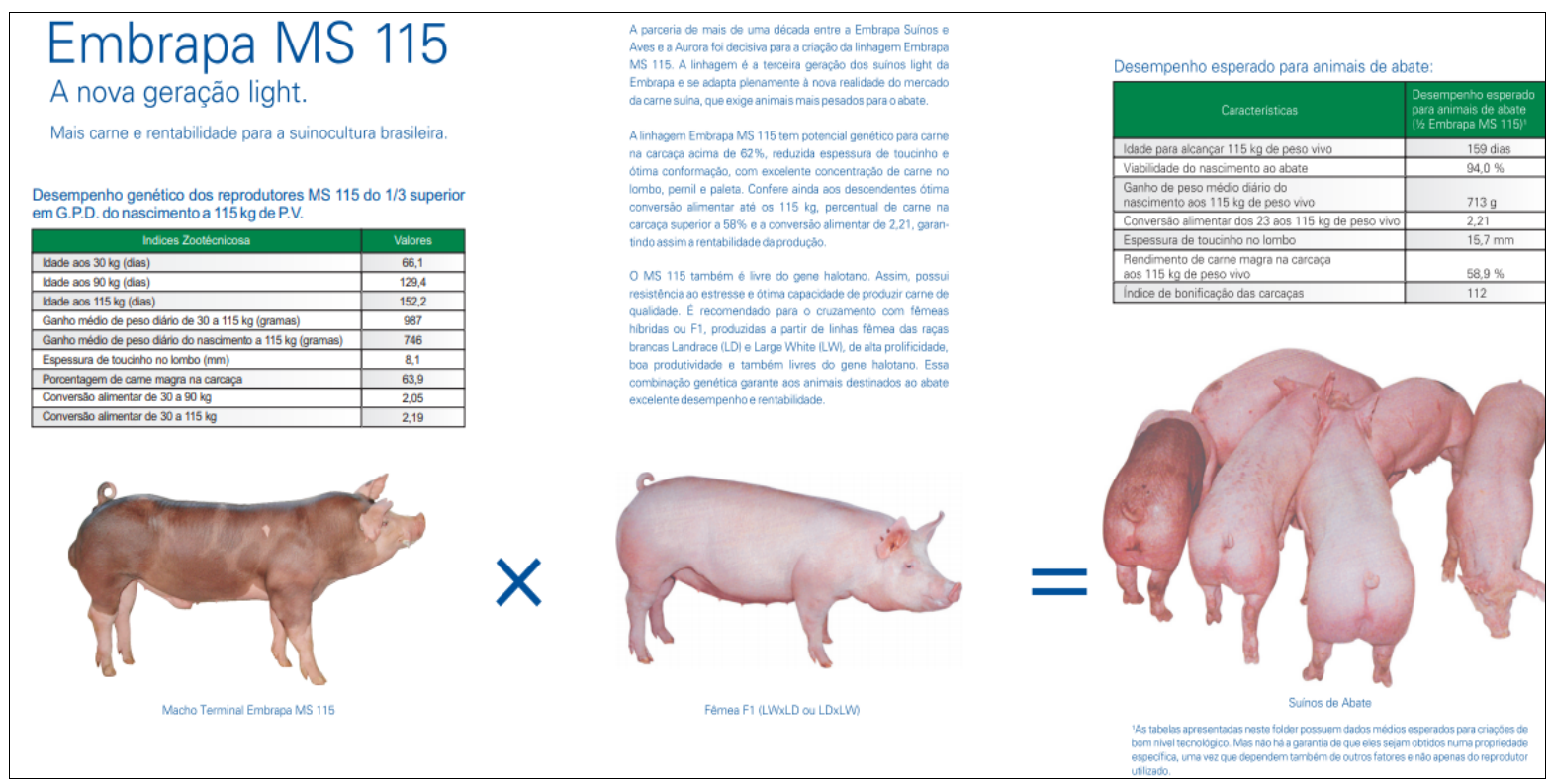

Fonte: FOLDER Embrapa MS115: suíno light (2018).

Segundo Pertile (2008, p. 93), em 1975, a participação do estado de Santa Catarina estava no auge da produção de banha no mercado nacional, sendo 29\% do total. Em 1985, a produção diminuiu para 12\%. A modernização da agricultura acarretou o incentivo do consumo de óleos vegetais no lugar da banha, como o óleo de soja.

O agricultor Bruno Zimmermann relatou o incentivo para o consumo de óleo de soja no lugar da banha, um dos catalisadores na diminuição da produção suína sem melhoramento genético:

[...] é que nem a tal da banha, ela nunca fazia mal pra ninguém, só que daí depois, mais tarde, entrou aquele cultivo do soja. Então quando entrou o cultivo do soja, técnicos, médicos e essa equipe de gente mais graúda, ela se reuniu e chegarem na conclusão de botar na cabeça do agricultor, do colono, que o tal de banha faz mal. Porque quando foi começado o soja, daí logo entrou aquela indústria do óleo, pra tirar o óleo do grão e daí limparem ele, então pra eles vender ele na cozinha, já vamos falar assim, eles tinham de proibir a banha pra o óleo pegar acesso e foi o que aconteceu, o povo aceitou essa mudança. Hoje se você vê o pessoal do interior, principalmente o pessoal do interior, eles usam bem mais banha do que óleo de soja, óleo de soja serve só pra na hora de emergência, mas hoje no interior é a banha, mas não a banha que vem do frigorífico [...] a banha caseira. [...] Então, as coisas caseiras, que nem nós falamos assim, um suíno engordado com lavagem, com milho, com mandioca, com batata, o que nós usava, essa carne nunca fez mal. [...] 
Então, hoje muitas doença que são, vamos falar assim, incuráveis, o tal do câncer e outras doenças que aparecem, ela vem tudo em cima, principalmente, vamos falar uma palavra mais curto e seco: as coisas enlatadas. [...] porque os antigo que eu cheguei a conhecer muitos, pessoas de mais idade, eles usava a banha brincando, era quantia grande [...] porque a banha então é, quando eu me lembro, no início, quando era um guri, então não se vendia os suíno, vendia somente a banha, a banha tinha um preço e daí depois conseguiram trazer a banha negativa. Então porque entrou a técnica, então o suíno foi modificado, aquele tal do porco preto, ele foi modificado que chegava um suíno de $100 \mathrm{~kg}$ que não dava três kg de banha e daí dizia que este era o saudável [...] Não tinha banha, mas é que, o que ele comeu às vez, muitas vezes, as pessoas não sabia. Então se a gente para e pensa e conversa, assim do tempo do antigo, a vida era bem diferente. (ZIMMERMANN, 2017)

É possível perceber no relato de Zimmermann a rejeição inicial por parte dos agricultores em relação às novas raças de suínos, assim como a descrença em relação às recomendações alimentares de substituição do consumo da banha pelo óleo de soja, atribuindo essas recomendações estarem servindo a uma lógica mercadológica e relacionando seu consumo com doenças. No início do sistema de produção integrada, os chamados porcos crioulos eram aceitos, o que foi sendo proibido em função dos riscos de contaminação que traziam. A recusa do consumo de carne do porco branco é comum principalmente em função da alimentação artificial fornecida a eles e do excesso de remédios aplicados, o que para os produtores altera o sabor da carne e prejudica a saúde dos consumidores.

Tabela 01: Quantidade da produção de banha e carne em Chapecó

\begin{tabular}{|c|c|c|}
\hline & Produção de banha & Produção de carne \\
\hline 1975 & 232 toneladas & 253 toneladas \\
\hline 1980 & 226 toneladas & 109 toneladas \\
\hline 1985 & 186 toneladas & 363 toneladas \\
\hline
\end{tabular}

Fonte: Tabela elaborada com base nos censos do IBGE.

Ao observara tabela 01, pode-se perceber que em 1975 ainda havia uma quantidade considerável de produção de banha em Chapecó, quantidade próxima a da produção de carne, sendo que, em 1985, a produção de banha decaiu e a carne se torna significativamente mais produzida. 
Em seu relato, Zimmermann defende que os porcos tratados com alimentos oriundos da policultura, presente no início da colonização, não faziam mal à saúde. Durante a entrevista, ele apresenta um histórico da alimentação utilizada para a engorda dos porcos, sendo no início utilizada a lavagem, que era composta por restos de batata, abóbora e mandioca, cozidas. Com a chegada de agrônomos na região, os produtores foram ensinados a utilizar o chamado cocho seco, que consistia em misturar ingredientes secos como quirera, farinha de osso, de carne e sais minerais para a alimentação dos suínos. Depois, com o desenvolvimento da agroindústria e a produção integrada, o consumo de ração se tornou exigência para a comercialização de suínos.

\section{O Oeste em pauta: os incentivos à produção em larga escala}

A industrialização da região Oeste foi ponto de pauta em diversas discussões, principalmente em âmbito político, já que os rumos tomados pela economia influenciavam na receita arrecadada pelo Estado. Devido ao fato de não existirem muitos frigoríficos, sendo que os suínos criados na região muitas vezes eram destinados para empresas fora do estado, chegou a ser levada para discussão na Assembleia Legislativa do Estado a possibilidade de proibir as exportações de suínos para outros estados. $\mathrm{Na}$ ocasião, posicionando-se contra tal medida, o deputado Vicente João Schneider argumentou que

(...) Com a implantação da medida apontada os nossos criadores de suinos necessariamente ficariam dependendo dos proprietários de frigorificos, localizados em nosso Estado. Estes são uns poucos; áquele são o grande número de criadores de suinos. Ora a discrepância entre uns e outros está patente. Para tal verificar, basta uma vista d'olhos sôbre a situação econômica do Estado nêste setôr. Os nossos frigorificos além de poucos, tanto absolutamente, como em relação aos criadores, foram adatados ao meio; não tem grandes capacidades de absorção de matéria prima, salvo raras exceções, e além disto, espalhados como estão serve cada um de por si a determinada zona criadora; enquanto que grandes regiões, também criadoras ficam na dependência dos frigorificos de outros Estados vizinhos, no tocante a industrialização da matéria prima. E sem a industrialização não há razão de ser, para a nossa grande criação de suinos.[...] Si esta cidade não ofereceria dezenas de possibilidades - o interior do Estado as teria as dezenas; como por exemplo - "A instalação d'um frigorífico no vale do rio Uruguai, que como zona criadora de suínos apresentaria farta matéria prima, para um 
estabelecimento desse gênero. Os criadores de suinos, (na hipótese de efetivada a proibição) ficariam na dependência, sómente dos nossos frigorificos, pois, impedidos de exportá-los estariam forçados a reduzir os seus rebanhos, senão de desistir da criação, dado o desânimo geral pela falta de mercado, nestas grandes regiões desprovidas de frigorificos e a precariedade das rodovias e as grandes distâncias para alcançar uma fábrica em nosso Estado. Nestas circunstâncias os suinocultores, desanimariam, desistiriam da "Grande Batalha da Produção, tão falada nos discursos atuais.(...) (SCHNEIDER, 1952, p. 2)

Dos pontos abordados pelo deputado em sua fala, a melhoria das rodovias e a diminuição da distância entre o produtor de matéria-prima e o local em que o produto poderia ser industrializado foram, nos anos que se seguiram, questões-chave para a integração definitiva da região oeste na economia catarinense. Para isso, tiveram destaque a produção de cultivos como milho, trigo e soja, e a criação de suínos e aves, entre outros produtos que complementavam a renda, como a extração vegetal. A problemática envolvendo o escoamento da produção continuava a ser notícia nos periódicos regionais mesmo depois de mais de uma década do pronunciamento de Schneider. Ainda assim, permanece o destaque para a agroindústria desenvolvida através da suinocultura e atividades de extração madeireira, já aparecendo também a necessidade de reflorestamento:

(...) O brilhante trabalho realizado pelos técnicos do $B R D E^{1}$ que só não foi mais autêntico pela falta de estatísticas recentes, engloba tôda a sistemática vital para a economia da região, demonstrando claramente que os setores prioritários do Oeste, são os ligados à suinocultura e florestamento, "devido às suas interrelações no conjunto da economia regional." [...] O estudo dos técnicos do BRDE evidencia a necessidade da presença dos governos, aliada à iniciativa particular, num plano de aproveitamento das potencialidades do Oeste Catarinense, principalmente: incentivando o florestamento e o reflorestamento, assistindo à suinocultura tecnicamente e assegurando-lhe melhores preços, instalando indústrias de transformação da matéria-prima abundante na área (milho, soja, suínos, madeiras, feijão), e uma adequada racionalização dos sistemas de transportes, através de melhores estradas, mais energia elétrica, comunicações eficientes com o restante do País e muito crédito. [...] De uma coisa, no entanto, os senhores leitores podem ter certeza o resultado de maior expressão na

\footnotetext{
${ }^{1}$ BRDE - após a divisão regional contemporânea, a sigla que antes era a abreviação de Banco Regional de Desenvolvimento Econômico, após a década de 1970, passou a denominar Banco Regional de Desenvolvimento do Extremo Sul.
} 
economia catarinense, dentro de breve futuro, está no Oeste Catarinense, e isso poderá ser uma gritante realidade tão pronto hajam condições satisfatórias de escoamento da produção, abastecimento de energia elétrica, comunicações adequadas e preços condizentes para a produção agrícola. As chaminés que geram o progresso industrial, aliadas à atividade agropecuária surgirão automaticamente. (FOLHA D'OESTE, 1968, p. 1 e 8)

O último trecho da notícia, que destaca o progresso industrial possibilitado pela atividade agropecuária, está presente na relação observada por Silva e Hass (2017) de um projeto político construído através da agroindústria. Para os autores, foi feita uma aliança político-empresarial organizada por meio dos ideais de progresso, em que os incentivos agroindustriais possibilitariam o desenvolvimento da região.

É nesse contexto, entre o final da década de 1960 e início de 1970, que o setor agroindustrial se consolidou no município, com a instalação da Cooperalfa em 1969, Aurora, a partir da massa falida do Frigorífico Marafon, em 1974, Ceval (antiga Extrafino), em 1971, e Sadia em 1973. Desenvolvimento que se deve a volumosos investimentos estatais, em créditos e nas vias de comunicação, melhorando a fluidez para o escoamento da produção local (RECHE, 2017).

Até então, a infraestrutura de estradas era vista como uma das principais dificuldades para o aporte e desenvolvimento do setor agroindustrial no Oeste. A Estrada de Ferro São Paulo-Rio Grande era incapaz, como aponta Espíndola (1999, p. 33), de conduzir os produtos nobres e refrigerados que então passaram a ser produzidos por essas empresas. As estradas, por outro lado, eram precárias (muitas ainda remanescentes das abertas pelas próprias colonizadoras), juntamente com limitações técnicas, como a ausência de refrigeração. Ainda na década de 1950, boa parte das rodovias da região carecia de pavimentação e pontes, e algumas das atuais rodovias que interligam a região sequer haviam sido projetadas ou possuíam tráfego intermitente, sendo que a atual BR 116, que cruzava o município de Lages, se distanciava mais de $300 \mathrm{~km}$ do município de Chapecó (SANTA CATARINA, 1958). Para contornar esse problema, empresas como a Sadia, de Concórdia e a Perdigão, de Videira, chegaram a utilizar transporte aéreo para o transporte de produtos como lombo, salame e presunto a mercados como São Paulo e Rio de Janeiro (ESPÍNDOLA, 1999). Em Chapecó, conforme Zolet (2006), os produtos das 
empresas locais também chegaram, na mesma época, a serem transportados via avião, para os centros consumidores.

A necessidade de maior fluidez para a produção local fica expressa em diversos discursos empreendidos por políticos e empresários locais sobre a urgência na melhoria das estradas e na abertura de novas rodovias. Reportagens veiculadas na imprensa local, como no jornal Folha D’Oeste de 1968, deixam clara essa preocupação, citando o caso da BR 282, bem como criticam a lentidão da obra:

É tão grande a descrença com relação à BR 282 que as autoridades estaduais já estudam a possibilidade de construção de uma nova rodovia, no prosseguimento que ligará Chapecó e Seara, atingindo Concórdia, Capinzal, Campos Novos e Curitibanos. Enquanto isso o trânsito do extremo oeste está sendo totalmente desviado para o Paraná, aproveitando as boas condições da estrada aberta pela Secretaria do Oeste, entre São Miguel d'Oeste e São Lourenço d'Oeste. Outra medida que desafoga o trânsito do Extremo Oeste, é a retificação da estrada Mondaí-Palmitos-São Carlos-Chapecó, presentemente também em obras pela Secretaria do Oeste (FOLHA D'OESTE, 1968, P.1).

As agroindústrias já instaladas, além daquelas que passaram a se instalar no município através de massivos incentivos estatais, tornaram o município atraente para a mão de obra migrante, composta de uma significativa parcela de antigos moradores da área rural que não se adequaram ao modelo imposto pela modernização agrícola e integração às agroindústrias. Esse fluxo também modelou a paisagem urbana de um município que, entre as décadas de 1970 e 1980, crescia a uma taxa de 11\% ao ano, frente a uma média nacional de $4,4 \%$ ao ano. Esse crescimento habitacional não foi absorvido totalmente pelas empresas locais, dando origem a diversos problemas sociais no município até os dias atuais, relacionados principalmente à habitação e ocupação das periferias da cidade, geralmente descoladas da malha urbana e próximas às agroindústrias (NASCIMENTO, 2017; RECHE, 2017).

Houve uma grande busca pela importação dos produtos das agroindústrias. A partir da década de 1990, a agroindústria passa a se reestruturar, buscando além da maior inserção internacional, a diversificação dos produtos, atendendo às novas exigências dos consumidores. Esse enfoque na exportação de suínos alterou o sistema de produção 
baseado na agricultura familiar, visto que foi constante nesse novo objetivo o incremento tecnológico e o aumento de escala (MIELE; WAQUIL, 2007, p. 75).

O engenheiro agrônomo, Mário Lanznaster, presidente da Cooperativa Central Aurora Alimentos, observa a importância da exportação de carne suínas da Aurora, sediada em Chapecó: “o Brasil se tornou o quarto maior exportador mundial de carne de suíno também, né? A Aurora exporta bem, o que mais exporta é a Aurora hoje. Por quê? Porque nós estamos num estado livre de aftosa sem precisar vacinar".

\section{A relação da produção animal e a diminuição das áreas florestais}

A composição florestal da região de Chapecó também foi alterada no período. Anteriormente, o espaço era ocupado pela Floresta Ombrófila Mista (FOM) e pela Floresta Estacional Decidual (FED), que foi sendo reduzida, de acordo com a exploração madeireira. A madeira obtida com a extração das árvores nativas forneceu grandes lucros desde o início da colonização, e a necessidade cada vez maior de ampliar as áreas destinadas para as atividades de agricultura e pecuária para atender às demandas da agroindústria teve como consequência a continuação do desmatamento em todas as fases do desenvolvimento. Além da intensa degradação ambiental causada pela retirada da vegetação nativa, a inserção de espécies exóticas também contribuiu para a descaracterização da paisagem da região.

Através dos dados fornecidos pelos censos agropecuários realizados entre 1960 e 1985, pode-se perceber que houve uma grande redução na área das matas e florestas naturais em Chapecó. Conforme Nodari (2012), os anos de 1960 e 1970 marcaram o auge da exploração da FED no estado, e as demonstrações do censo de áreas de matas naturais em Chapecó entre esse período apresentam uma redução de 49.317 hectares, em 1960, para 17.547 hectares, em 1970. Por outro lado, o crescimento de áreas de matas e florestas reflorestadas não ocorreu na mesma proporção com que as áreas naturais foram diminuídas, como podemos observar na tabela abaixo. 
Tabela 02: Áreas de floresta entre 1960 e 1985

\begin{tabular}{|c|c|c|c|c|c|}
\hline & 1960 & 1970 & 1975 & 1980 & 1985 \\
\hline Matas naturais & $49.371 \mathrm{ha}$ & $17.547 \mathrm{ha}$ & $11.877 \mathrm{ha}$ & $11.817 \mathrm{ha}$ & $10.639 \mathrm{ha}$ \\
\hline Matas reflorestadas & $2.222 \mathrm{ha}$ & $1.560 \mathrm{ha}$ & $1.395 \mathrm{ha}$ & $1.807 \mathrm{ha}$ & $4.001 \mathrm{ha}$ \\
\hline
\end{tabular}

Fonte: Tabela elaborada com base nos censos do IBGE.

Em 1969, a extração vegetal representava "38,2\% do valor da produção oestina, somente perdendo para as indústrias de produtos alimentícios (frigoríficos, etc.) que representam 56,1\%" (FOLHA D’OESTE, 1969, p. 1). A extração madeireira decaía paralelamente ao aumento da suinocultura e da agroindústria. De acordo com o Censo divulgado pela EPAGRI (Empresa de Pesquisa Agropecuária e Extensão Rural de Santa (atarina), citado na tabela 03, pode-se observar que houve um aumento no número de suínos e na produção de milho, destinado à ração animal.

Tabela 03: Comparação entre produção de suínos, milho e extração madeireira

\begin{tabular}{|c|c|c|}
\hline Produção & 1960 & 1970 \\
\hline Suínos & 1244632 & 3.145 .337 \\
\hline Milho & 687.357 toneladas & 1.197.587 toneladas \\
\hline Madeira & $\begin{array}{c}5201 \mathrm{~m}^{3} \text { de lenha } \\
6653 \mathrm{~m}^{3} \text { de madeira em toras }\end{array}$ & $\begin{array}{l}14 \mathrm{mil} \mathrm{m}^{3} \text { de lenha } \\
3 \mathrm{mil} \mathrm{m} \text { de madeira }\end{array}$ \\
\hline
\end{tabular}

Fonte: DUFLOTH, J. H; et.al., 2005.

A madeira destinada como lenha para suprir a agroindústria também aumentou, enquanto a extração madeireira, voltada para as serrarias, diminuiu. Esses dados podem ser interpretados, visualizando que a redução de $\mathrm{m}^{3}$ processados em toras, que significava não somente a diminuição de árvores nativas, causada pela exploração predatória, mas também, o fechamento das serrarias e o crescimento de outros setores da economia, como a suinocultura e outras atividades ligadas diretamente à agroindústria.

Os problemas ambientais acarretados com a suinocultura são muitos e normalmente ligados apenas à poluição causada por dejetos e uso indiscriminado de água potável. No entanto, é momentoso destacar a degradação florestal relacionada a esta produção. Em publicação da EMBRAPA, os organizadores reconhecem que "os modelos 
de produção agrícola mais difundidos no mundo nas últimas quatro décadas priorizaram a eficiência técnica e econômica, onde a produtividade física foi aumentada de forma expressiva, com o objetivo de suprir a demanda de mercado e maximização dos lucros" (MIRANDA, C.; MIELE, M., 2009, p. 15).

\section{Considerações Finais}

A região oeste de Santa Catarina estabeleceu relações comerciais com o Rio Grande do Sul e São Paulo, principalmente devido à facilidade do transporte da banha via ferrovia na região do Vale do Rio do Peixe. A inserção no mercado de São Paulo possibilitou a introdução da região no mercado nacional, provocando um aumento das produções dos frigoríficos.

Em 2006, os dados do IBGE continuam a apresentar a predominância da agricultura familiar na atividade agropecuária. Conforme o Plano de Desenvolvimento Rural de Chapecó de 2015, estima-se a inserção de 90\% da população rural do estado no modelo de agricultura familiar, ocupando $41 \%$ das áreas exploradas. Cerca de 194 mil propriedades rurais ocupam mais de seis milhões de hectares, sendo 80\% áreas de menos de 50 hectares (destinadas à produção familiar). A agricultura familiar abrange em torno de 70\% da produção agropecuária municipal (CHAPECÓ, 2015, p. 95).

Houve a diminuição da área florestal no oeste do estado. A produção de suínos está amplamente conectada com a degradação ambiental, principalmente por conta dos dejetos produzidos. Há cobrança ambiental das empresas sobre os seus produtores, "percebe-se que essas exigências estão mais relacionadas aos aspectos legais da questão (obtenção do licenciamento) do que propriamente a um esforço integrado para que os produtores entendam as questões ambientais como exigências importantes e necessárias" (MIRANDA; MIELE, 2009, p. 167). A regeneração da floresta nativa também depende do ambiente sem a presença de poluentes, e a poluição dos rios e mananciais são agravantes e ameaçam até mesmo áreas de preservação. Constatou-se também que a diminuição das áreas florestais ocupadas pela floresta nativa estimulou a criação de animais a solta, pois reduziu os recursos alimentícios para os animais, provindos da floresta. 
As mudanças na estrutura produtiva da criação de suínos, notadamente a partir das décadas de 1960 e 1970 com a difusão da integração, marcando um aumento da subordinação dos produtores ao setor agroindustrial, acentuaram de forma significativa o processo de degradação ambiental da região. O crescimento da produção e a consequente concentração produtiva na região não vieram acompanhados de preocupações ambientais, fazendo com que fontes de água, rios e o subsolo sofressem com o descarte sem nenhum tratamento dos dejetos animais, resultando em altos índices de contaminação desses recursos. Da mesma forma, as lavouras, fundamentais dentro do chamado binômio milho/porco, também passam pelo aumento significativo da área cultivada e da intensificação do uso de agrotóxicos, acarretando uma série de problemas ambientais que afetam, ainda hoje, de forma intensa a população oestina tanto das áreas rurais, quanto urbanas (FORNECK E KLUG, 2015, CARVALHO E NODARI, 2017).

\section{Referências}

BAVARESCO, Paulo Ricardo. A história econômica do oeste catarinense. In: Mirian Carbonera et al. (Orgs.). Chapecó 100 anos: histórias plurais. 1 ed. Chapecó: Argos, 2017, p. 281-313.

BOSSLE, Ondina Pereira. História da industrialização catarinense: das origens à integração no desenvolvimento brasileiro. 2. Ed. Florianópolis: CNI/Fiesc, 1988.

BRANDT, Marlon; NODARI, Eunice Sueli. Comunidades tradicionais da Floresta de Araucária de Santa Catarina: territorialidade e memória. História Unisinos, São Leopoldo, v. 15, n. 1, p. 80-90, 2011.

BRANDT, Marlon. Uma história ambiental dos Campos do Planalto de Santa Catarina. 2012, 332 f. Tese (Doutorado em História) - Centro de Filosofia e Ciências Humanas, Universidade Federal de Santa Catarina, Florianópolis, 2012.

BRANDT, Marlon. Criação de porcos “à solta” na Floresta Ombrófila Mista de Santa Catarina: paisagem e uso comum da terra. História (São Paulo. Online), v. 34, p. 303-322, 2015.

BRDE prova que a economia do Oeste está na suinocultura e na extração de madeiras. Folha d'Oeste. Diretores Homero Franco e Gabriel Dezen. Chapecó, 16 de novembro de 1968, ano V, n. 174, p. 1 e 8. 
CARVALHO, Miguel Mundstock Xavier de; NODARI, Eunice Sueli; NODARI, Rubens Onofre. "Defensivos" ou "agrotóxicos"? História do uso e da percepção dos agrotóxicos no estado de Santa Catarina, Brasil, 1950-2002. História, ciência, saúde-Manguinhos, Rio de Janeiro, v. 24, n. 1, p. 75-91, jan. 2017.

CHAPECÓ. Lei n 12, de 24 de março de 1970. Concede benefícios as indústrias que se estabelecerem no município de Chapecó. Diário Oficial do Município, Chapecó, SC, 24 mar. 1970. Disponível em: <https://leismunicipais.com.br/a/sc/c/chapeco/leiordinaria/1970/2/12/lei-ordinaria-n-12-1970-concede-beneficios-as-industrias-que-seestabelecerem-no-municipio-de-chapeco?q=terraplanagem>. Acesso em: 25 jun. 2018.

CORRÊA, Roberto Lobato. O sudoeste paranaense antes da colonização. Revista Brasileira de Geografia, Rio de Janeiro, n. 1, ano 32, p. 87-98, jan/mar. 1970.

CROSBY, Alfred W. Imperialismo ecológico: a expansão biológica da Europa (900-1900). São Paulo: Companhia das Letras, 1993.

DEAN, Warren. A ferro e fogo: a história e a devastação da Mata Atlântica. São Paulo: Companhia das Letras, 2004.

Definição de porco tipo carne. Folha d'Oeste. Chapecó, 10 de janeiro de 1970, ano VI, n. 230, p. 6.

DUFLOTH, J. H; et.al. (Org.). Estudos básicos regionais de Santa Catarina. Florianópolis: EPAGRI, 2005. 1 CD ROM.

EMBRAPA. Porco light tem mais carne e dá mais lucro. 01/07/96. Disponível em: <https://www.embrapa.br/busca-de-noticias/-/noticia/17911977/porco-light-tem-maiscarne-e-da-mais-lucro>. Acesso em 26 jun. 2018.

EMPRESA CATARINENSE DE PESQUISA AGROPECUÁRIA. Relatório anual 1976. In: EMPRESA DE PESQUISA AGROPECUÁRIA E EXTENSÃO RURAL DE SANTA CATARINA. Coletânea dos trabalhos editados pela EPAGRI: Relatório anual. Chapecó: Epagri, 1993.

Estradas péssimas. A voz de Chapecó. 30/07/1939. N. 13 Página:4 Coluna: 4. Acervo BPESC.

ESPÍNDOLA, Carlos José. As agroindústrias do Brasil: o caso Sadia. Chapecó: Grifos, 1999.

FERRARI, Maristela. Conflitos e povoamento na zona de fronteira internacional BrasilArgentina: Dionísio Cerqueira (SC), Barracão (PR) e Bernardo de Irigoyen (MNES. ARG). 2003. 290 fl. Dissertação (Mestrado em Geografia) - Centro de Filosofia e Ciências Humanas, Universidade Federal de Santa Catarina, 2003. 
FOLDER Embrapa MS115: suíno light. Concórdia: Embrapa Suínos e Aves, 2008. Disponível em: <http://ainfo.cnptia.embrapa.br/digital/bitstream/item/168481/1/MS-115-8-imp..pdf>. Acesso em 20 ago. 2018.

FORNECK, Elisandra; LUBENOW, Aline Maisa. Cooperativismo, modernização agrícola e desenvolvimento econômico no oeste catarinense. In: Mirian Carbonera et al. (Orgs). Chapecó 100 anos: histórias plurais. 1 ed. Chapecó: Argos, 2017, p. 315-356.

FORNECK, Elisandra; KLUG, João. Suinocultura no oeste catarinense: do desastre ambiental à busca de equilíbrio. In: NODARI, Eunice Sueli; ESPÍNDOLA, Marcos Aurélio; LOPES, Alfredo Ricardo. (Org.). Desastres Socioambientais em Santa Catarina. São Leopoldo: Oikos, 2015.

CARVALHO, Miguel Mundstock Xavier de; NODARI, Eunice Sueli; NODARI, Rubens Onofre. "Defensivos" ou "agrotóxicos"? História do uso e da percepção dos agrotóxicos no estado de Santa Catarina, Brasil, 1950-2002. História, ciência, saúde-Manguinhos, Rio de Janeiro, v. 24, n. 1, p. 75-91, jan. 2017.

FUNDAÇÃO INSTITUTO BRASILEIRO DE GEOGRAFIA E ESTATÍSTICA. Censo Agropecuário Santa Catarina. Censos econômicos de 2006. Rio de Janeiro, IBGE: 2009.

IBGE. Porcos no frigorífico SAIC em Chapecó (SC), 1957. Série: Acervo dos trabalhos geográficos de campo. Disponível em: https://biblioteca.ibge.gov.br/index.php/bibliotecacatalogo?view=detalhes\&id=421899 Acesso 10 de abril de 2018.

INSTITUTO BRASILEIRO DE GEOGRAFIA E ESTATÍSTICA. Séries estatísticas retrospectivas, v. II, tomo II. Rio de Janeiro: IBGE, 1986.

LAGO, Paulo Fernando. Gente da terra catarinense - desenvolvimento e educação ambiental. Florianópolis: Ufsc/FCC/Lunardelli/Udesc, 1988.

LANZNASTER, Mário. Entrevista a Mario Lanznaster concedida a Andressa Krieser Bauermann e Marlon Brandt. Chapecó, 2017. Acervo do projeto de extensão Memória histórico-geográfica do Planalto e Oeste de Santa Catarina: imagens e oralidades.

MACHADO, Isabel Cristina; MARANGONI, Sheila; HEFFEL, Patricia. 15 anos Abrindo as portas para a qualidade. Chapecó: Aurora Alimentos - T12, 2013.

MACHADO, Roberto. O Calor do Frigorífico. O Imparcial: Jornal Independente. Diretor proprietário Alexandre Tiezerini. Chapecó, 13 de julho de 1952, ano II, n. 68, p. 1.

MIELE, M.; WAQUIL, P. D. Cadeia produtiva da carne suína no Brasil. Revista de Política Agrícola, v. 16, n. 1, p. 75-87, jan./mar. 2007. 
Ministro Andreazza ainda não cumpriu sua promessa de inaugurar frente de trabalho na BR-282. Folha d'Oeste. Diretores Homero Franco e Gabriel Dezen. Chapecó, 17 de agosto de 1968, ano V, n. 161, p. 1.

MIRANDA, Claudio Rocha; MIELE, Marcelo. Suinocultura e Meio Ambiente em Santa Catarina: Indicadores de desempenho e avaliação sócio-econômica. Concórdia: Embrapa Suínos e Aves, 2009.

NASCIMENTO, Ederson. A segregação socioespacial em Chapecó: formação históricogeográfica e tendências contemporâneas. In: NASCIMENTO, Ederson, VILLELA, Ana Laura Vianna. (Orgs). Chapecó em foco: textos e contextos sobre o espaço urbano-regional. São Carlos: Pedro \& João Editores, 2017, p. 105-154.

NODARI, Eunice Sueli. Etnicidades renegociadas: práticas socioculturais no Oeste de Santa Catarina. Florianópolis: Ed. da UFSC, 2009.

NODARI, Eunice Sueli. "Mata Branca": o uso do machado, do fogo e da motosserra na alteração da paisagem de Santa Catarina. In: NODARI, Eunice Sueli; KLUG, João (Orgs). História Ambiental e Migrações. São Leopoldo: Oikos, 2012, p. 35-53.

OLINGER, Glauco. Siga êste livro e crie suínos. 3. Ed. Florianópolis: [s.I], 1969.

PAIM, Elison Antonio. Aspectos da constituição histórica da região oeste de Santa Catarina. Saeculum Revista de História, João Pessoa, n. 14, p. 121-138, jan./jun. 2006.

PERTILE, Noeli. Formação do espaço agroindustrial em Santa Catarina: o processo de produção de carnes no oeste catarinense. Tese (Doutorado em Geografia). UFSC, Florianópolis, 2008.

QUEIROZ, Maurício Vinhas de. Messianismo e conflito social: a guerra sertaneja do Contestado (1912-1916). 3. ed. São Paulo: Ática, 1981. Coleção Ensaios, n. 23.

RECHE, Daniella. O Estado e a produção do espaço urbano de Chapecó nas décadas de 1970 e 1980. In NASCIMENTO, Ederson, VILLELA, Ana Laura Vianna. (Orgs). Chapecó em foco: textos e contextos sobre o espaço urbano- regional. São Carlos: Pedro \& João Editores, 2017, p. 37-63.

RENK, Arlene Anélia. A luta da erva: um ofício étnico da nação brasileira no oeste catarinense. 2. ed. Chapecó: Argos, 2006.

SANTA CATARINA. Atlas Geográfico de Santa Catarina. Florianópolis: Departamento Estadual de Geografia e Cartografia, 1958.

SANTOS, Milton. A natureza do espaço: técnica e tempo, razão e emoção. 4 ed. São Paulo: Edusp, 2006. 
SCHNEIDER, Vicente. Em defesa dos Suinocultores. O Imparcial: Jornal Independente. Diretor proprietário Alexandre Tiezerini. Chapecó, 24 de agosto de 1952, ano II, n. 74, p. 2.

SILVA, Claiton Marcio da; HASS, Monica. "O Oeste Catarinense não pode parar aqui". Política, agroindústria e uma história do ideal de progresso em Chapecó (1950-1969). Revista Tempo e Argumento, Florianópolis, v. 9, n. 21, p. 338 - 374. maio/ago. 2017.

VALENTINI, Delmir José. O tropeirismo de suínos na região do Contestado e sua influência no incipiente processo agroindustrial. In: ZOTTI, Solange Aparecida (org). História faz história: contribuições ao estudo da história regional. Concórdia: UnC, 2006.

WAIBEL, Léo. Princípios da colonização européia no Sul do Brasil. Revista Brasileira de Geografia, Rio de Janeiro, v. 12, n. 2, p. 159-222, abr/jun., 1949.

ZIMMERMANN, Bruno. Entrevista a Bruno Zimmermann concedida a Andressa Krieser Bauermann. Pinhalzinho, 2017. Acervo do projeto de extensão Memória históricogeográfica do Planalto e Oeste de Santa Catarina: imagens e oralidades.

ZOLET, Victorino B; SILVESTRIN, Alvírio (orgs). 50 anos fotografando Chapecó: uma coletânea de mais de 500 fotos. Chapecó: Ed. do Autor, 2006.

Recebido em 25/09/2018 Aprovado em 14/02/2019

Universidade do Estado de Santa Catarina - UDESC Programa de Pós-Graduação em História - PPGH Revista Tempo e Argumento Volume 11 - Número 26 - Ano 2019 tempoeargumento@gmail.com 